\title{
Development and Application of a Novel Green Water-Based Drilling Fluid
}

\author{
Hongjiang Li
}

SINOPEC Oilfield Service Corporation, Beijing 100020, China

Corresponding Author Email: lihongjiang.os@ @inopec.com

https://doi.org/10.18280/eesrj.080107

Received: 5 December 2020

Accepted: 19 February 2021

\section{Keywords:}

water-based drilling fluid, treatment agent, green development, field application

\begin{abstract}
In response to the technical and environmental protection requirements of water-based drilling fluids, this study independently developed a series of green supporting treatment agents for water-based drilling fluids such as the green loss reducer HB-1, green inhibitor HB-2, and green lubricant HB-3, etc., and proposed a green water-based drilling fluid system (HBDF) with good comprehensive performance. The proposed system has a heat resistance of $150^{\circ} \mathrm{C}$, a HTHP (high temperature and high pressure) filtrate loss of $12 \mathrm{~mL}$, a biological toxicity $\mathrm{EC}_{50}$ value greater than $10^{5} \mathrm{mg} / \mathrm{L}$, and a biodegradability $\mathrm{BOD}_{5} / \mathrm{COD}_{\mathrm{Cr}}$ value of $16.2 \%$. Now the developed HBDF system has been applied in more than 10 wells in SL oilfield, and the field application results show that the proposed HBDF system has stable rheological and filtrate loss performance, good anti-pollution ability, and easy and simple maintenance operations; after drilling, the biological toxicity of the drilling fluids can meet the environmental protection requirements, which has provided a technical reference for the research of green drilling fluids and the green development of SL Oilfield.
\end{abstract}

\section{INTRODUCTION}

In recent years, the Chinese government has enforced more stringent laws and regulations for environmental protection, and successively enacted a new environmental protection law (2015) which is the strictest one ever, and the first environmental tax law (2018), requiring that the wastes generated during oil and gas exploitation such as drilling fluids, oil-containing cuttings, and oil-containing sludge that do not meet the discharge standards must be fully recycled and subject to bio-safety disposal treatment, otherwise high environmental protection taxes will be imposed on them, and now the environmental protection situation of drilling projects is getting more severe than ever [1-4]. The currently-adopted bio-safety disposal treatment methods of waste drilling fluids have a few shortcomings such as complex processing techniques, large equipment investment, high treatment cost, and incomplete treatment effect, and they cannot effectively solve the environmental pollution problem of waste drilling fluids $[5,6]$. Therefore, developing green water-based drilling fluid systems is an important means to control the pollution caused by drilling fluids from the source and realize green drilling and clear production. However, the green water-based drilling fluid systems developed in early years, such as the polyalcohol drilling fluids, formate drilling fluids, silicate drilling fluids, and alkyl polyglucoside drilling fluids [7-9] failed to be promoted and applied due to high cost or unsatisfactory application effect.

In view of the technical requirements of green water-based drilling fluids, this study developed a series of green supporting treatment agents for water-based drilling fluids based on natural polymers, and proposed a new-type green water-based drilling fluid system (HBDF) with good comprehensive performance. In this way, the treatment of waste drilling fluids has transformed from "end treatment" to "source treatment". Now the developed HBDF system has been applied in more than 10 wells on real oilfield site, and this study has provided a technical support for the development of green drilling fluids for SL Oilfield.

\section{RESEARCH AND EVALUATION OF KEY TREATMENT AGENTS FOR GREEN WATER-BASED DRILLING FLUIDS}

\subsection{Green filtrate loss reducer $\mathrm{HB}-1$}

Through molecular structure design and synthesis condition optimization, with corn starch as the raw material and the "etherification-crosslinking" as the compound modification method, the green filtrate loss reducer HB-1 was developed based on modified starch [10-13]. According to Table 1, compared with other starch-based filtrate loss reducers, the proposed green filtrate loss reducer HB-1 exhibited good filtrate loss performance in both fresh water slurry and salt water slurry, and the API filtrate loss after hot rolling at $150^{\circ} \mathrm{C}$ is less than $10 \mathrm{~mL}$. In addition, environmental performance results show that the biological toxicity $\mathrm{EC}_{50}$ value of $\mathrm{HB}-1$ is $96500 \mathrm{mg} / \mathrm{L}$, and the biodegradability $\mathrm{BOD}_{5} / \mathrm{COD}_{\mathrm{Cr}}$ value is $20.6 \%$, which can meet the environmental protection requirements of "non-toxic and easily biodegradable".

\subsection{Green inhibitor HB-2}

Aiming at the complex downhole conditions and drilling problems such as soft upper-layer strata, fast mechanical drilling speed, easy drilling mud and bit balling producing, borehole diameter shrinking, and difficult hoisting or running 
operations [14], the composite salt green inhibitor HB-2 was developed; then, with shale rolling recovery rate as the evaluation indicator, the hydration inhibition performance of HB-2 was evaluated and compared with other inhibitors. According to Table 2, the clear water rolling recovery rate of natural rock samples is only $11.8 \%$, and the rolling recovery rate of HB-2 has significantly increased to $67.9 \%$, which is equivalent to the performance of amino-silanol AP-1, both are good at inhibiting clay hydration dispersion.

Table 1. Experimental results of filtrate loss reducer HB-1

\begin{tabular}{ccccc}
\hline Fluids & $\mathrm{FL}_{\mathrm{API}} / \mathrm{mL}$ & $\mathrm{AV} / \mathrm{mPa} \cdot \mathrm{s}$ & $\mathrm{PV} / \mathrm{mPa} \cdot \mathrm{s}$ & $\mathrm{YP} / \mathrm{Pa}$ \\
\hline 4\%bentonite & 38.0 & 3.5 & 2.5 & 1.0 \\
slurry & & 14.0 & 8.5 & 5.5 \\
$+1.5 \% \mathrm{HB}-1$ & 7.2 & 17.5 & 12.0 & 5.5 \\
$+1.5 \% \mathrm{HCMS}$ & 10.2 & 7.0 & 5.0 & 2.0 \\
$+1.5 \% \mathrm{FLO}$ & 13.6 & 4.5 & 3.0 & 1.5 \\
\hline 4\%salt slurry & 42.8 & 11.5 & 7.0 & 4.5 \\
$+1.5 \% \mathrm{HB}-1$ & 9.6 & 10.0 & 7.0 & 3.0 \\
$+1.5 \% \mathrm{HCMS}$ & 12.0 & 6.0 & 5.0 & 1.0 \\
$+1.5 \% \mathrm{FLO}$ & 15.2 & & & \\
\hline
\end{tabular}

Table 2. Experimental results of inhibitor HB-2

\begin{tabular}{cc}
\hline Fluids & Rolling recovery rate $\%$ \\
\hline Fresh water & 11.8 \\
$2 \% \mathrm{HB}-2$ & 67.9 \\
$2 \% \mathrm{AP}-1$ & 70.2 \\
$2 \% \mathrm{KCl}$ & 41.3 \\
$2 \% \mathrm{JLX}-\mathrm{C}$ & 27.1 \\
\hline
\end{tabular}

\subsection{Green lubricant HB-3}

With waste vegetable oil as the raw material, through esterification and transesterification reactions and hightemperature resistance modification processing, the vegetable oil green lubricant HB-3 was developed. According to Table 3 , after adding $2 \% \mathrm{HB}-3$ into $4 \%$ bentonite slurry, the reduction rate of extreme pressure lubricity coefficient and the reduction rate of mud-cake adhesion coefficient can reach $92.7 \%$ and $86.7 \%$, respectively, the lubrication performance of HB-3 is better than that of oil-based lubricants, ester-based lubricants, polyether lubricants and other common lubricants. Meanwhile, the vegetable oil green lubricant HB-3 is nontoxic and easily biodegradable, its $\mathrm{EC}_{50}$ value is greater than $30000 \mathrm{mg} / \mathrm{L}$, and the biodegradability $\mathrm{BOD}_{5} / \mathrm{COD}_{\mathrm{Cr}}$ value is greater than $15 \%$.
Table 3. Experimental results of lubricant HB-3

\begin{tabular}{ccc}
\hline Fluids & $\begin{array}{c}\text { Lubricity } \\
\text { coefficient } \\
\text { reduction rate/\% }\end{array}$ & $\begin{array}{c}\text { Mud-cake adhesion } \\
\text { coefficient reduction } \\
\text { rate/\% }\end{array}$ \\
\hline 2\%HB-2 & 92.7 & 86.7 \\
2\%LUBE-M & 72.6 & 34.6 \\
2\%ESTER & 89.4 & 31.7 \\
2\%ETHER & 81.6 & 40.4 \\
$2 \%$ LUBE-O & 90.7 & 66.3 \\
\hline
\end{tabular}

\section{THE PROPOSED GREEN WATER-BASED DRILLING FLUID SYSTEM AND ITS EVALUATION}

Based on the research and selection of key treatment agents for green water-based drilling fluids, through compatibility evaluation and treatment agent addition amount optimization, a new green water-based drilling fluid system (HBDF) was proposed. The specific formula is as: $3 \%$ bentonite slurry + $2 \%$ green filtrate loss reducer HB- $1+3 \%$ green inhibitor HB$2+2 \%$ green lubricant HB-3 $+0.3 \%$ cleaning flocculant HB$4+2 \%$ green anti-collapse agent HB- $5+0.03 \%$ flow pattern regulator HB-6. Then, the general properties of the HBDF system were evaluated, including the rheological and infiltrate loss performance, anti-pollution ability, plugging and anticollapse, hydration inhibition, lubrication, and the environmental protection performance, etc.

\subsection{Evaluation of rheological and infiltrate loss performance}

According to Table 4, the heat resistance of the HBDF system can reach $150^{\circ} \mathrm{C}$, the values of plastic viscosity before and after hot rolling are both within $30 \mathrm{mPa} . \mathrm{s}$, and the dynamic shear force is between $12 \sim 18 \mathrm{~Pa}$. It has the characteristics of low viscosity and high shear force, which is conductive to reducing the equivalent circulating density of the drilling fluids; the viscosity at low shear rate is moderate, which can effectively improve the cuttings-carrying capacity of the drilling fluids; the API filtrate loss is less than $5 \mathrm{~mL}$, the HTHP filtrate loss is less than $15 \mathrm{~mL}$, and the filtrate loss reduction performance is good, which can meet the drilling requirements on site.

Table 4. Rheological and infiltrate loss performance of HBDF fluids

\begin{tabular}{ccccccccc}
\hline Conditions & $\mathrm{AV} / \mathrm{mPa} . \mathrm{s}$ & $\mathrm{PV} / \mathrm{mPa} . \mathrm{S}$ & $\mathrm{YP} / \mathrm{Pa}$ & $\mathrm{Gel} / \mathrm{Pa}$ & $\Phi 6 / \Phi 3$ & $\mathrm{FL}$ API $/ \mathrm{mL}$ & $\mathrm{FLHTHP} / \mathrm{mL}$ & $\mathrm{pH}$ \\
\hline Before rolling & 48.0 & 30.0 & 18.0 & $4.0 / 9.5$ & $12.0 / 10.0$ & 3.0 & - & 9.0 \\
After rolling $120^{\circ} \mathrm{C}$ & 44.0 & 30.0 & 14.0 & $3.5 / 9.0$ & $11.0 / 9.5$ & 2.8 & 8.4 & 9.0 \\
After rolling $150^{\circ} \mathrm{C}$ & 41.5 & 29.0 & 12.5 & $2.0 / 8.0$ & $11.0 / 9.0$ & 4.2 & 12.0 & 9.0 \\
\hline
\end{tabular}

\subsection{Evaluation of anti-pollution performance}

With $10 \% \mathrm{NaCl}, 0.5 \% \mathrm{CaCl}_{2}$, and $10 \%$ evaluation soil taken as simulated pollutants, the anti-pollution performance of the HBDF system was evaluated by experiments. According to Table 5, after adding $10 \% \mathrm{NaCl}$ and $0.5 \% \mathrm{CaCl}_{2}$, the viscosity and shear-force of the HBDF system changed little, and the API filtrate loss after hot rolling is less than $5 \mathrm{~mL}$, indicating that the HBDF system has good resistance to salt and calcium pollution. After adding 10\% evaluation soil, the viscosity and shear-force of the HBDF system increased slightly, but the system maintained good rheological and infiltrate loss performance, indicating that the HBDF system has good resistance to soil pollution.

\subsection{Evaluation of hydration inhibition performance}

Rolling dispersion experiment and shale expansion experiment were performed to evaluate the inhibition performance of the HBDF system. Natural rock samples were 
selected and subject to the rolling dispersion experiment $\left(77^{\circ} \mathrm{C} / 16 \mathrm{~h}\right)$, and the experimental results show that the clear water rolling recovery rate of natural rock samples is only
$24.91 \%$, while the rolling recovery rate of the HBDF system is $94.11 \%$, indicating that the system has good performance in inhibiting clay hydration dispersion.

Table 5. Anti-pollution performance of HBDF fluids

\begin{tabular}{cccccccc}
\hline Fluids & Conditions & $\mathrm{AV} / \mathrm{mPa} . \mathrm{s}$ & $\mathrm{PV} / \mathrm{mPa} . \mathrm{S}$ & $\mathrm{YP} / \mathrm{Pa}$ & $\mathrm{Gel} / \mathrm{Pa}$ & $\mathrm{FL}$ API $/ \mathrm{mL}$ & $\mathrm{pH}$ \\
\hline $\mathrm{HBDF}$ & After rolling & 41.5 & 29.0 & 12.5 & $2.0 / 8.0$ & 2.8 & 9.0 \\
$+10 \% \mathrm{NaCl}$ & After rolling & 32.5 & 21.0 & 11.5 & $3.0 / 6.5$ & 3.2 & 8.5 \\
$+0.5 \% \mathrm{CaCl}_{2}$ & After rolling & 27.5 & 22.0 & 5.5 & $0.5 / 2.5$ & 4.0 & 8.0 \\
$+10 \%$ evaluation soil & After rolling & 45.5 & 31.5 & 14.0 & $1.0 / 4.5$ & 3.0 & 9.5 \\
\hline
\end{tabular}

In the shale expansion experiment, the linear expansion rate of the rock samples in clear water and in drilling fluid was measured, and the results show that the linear expansion rate of the rock samples in clear water is as high as $27.33 \%$, the initial expansion speed is fast and the expansion rate is high. The shale expansion rate of the HBDF system has greatly reduced, the value is only $7.27 \%$, indicating that the system has good performance in inhibiting clay hydration expansion.

\subsection{Evaluation of plugging and anti-collapse performance}

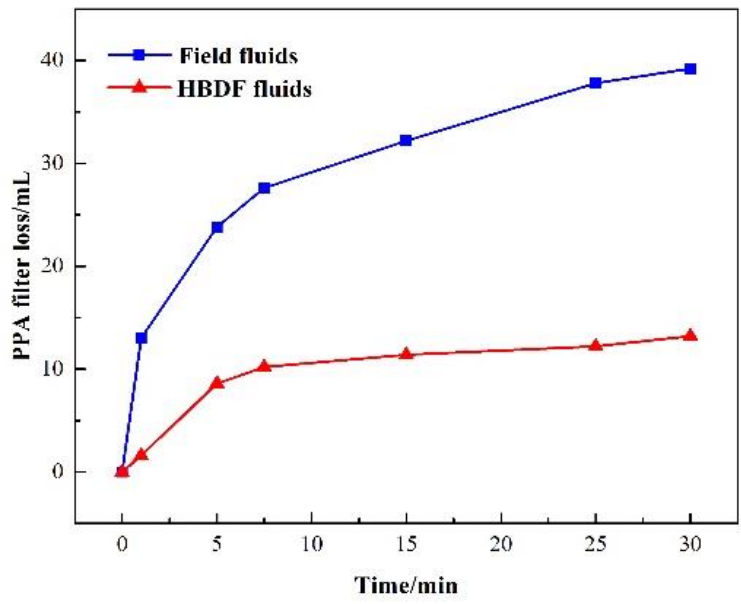

(a) PPA filter loss

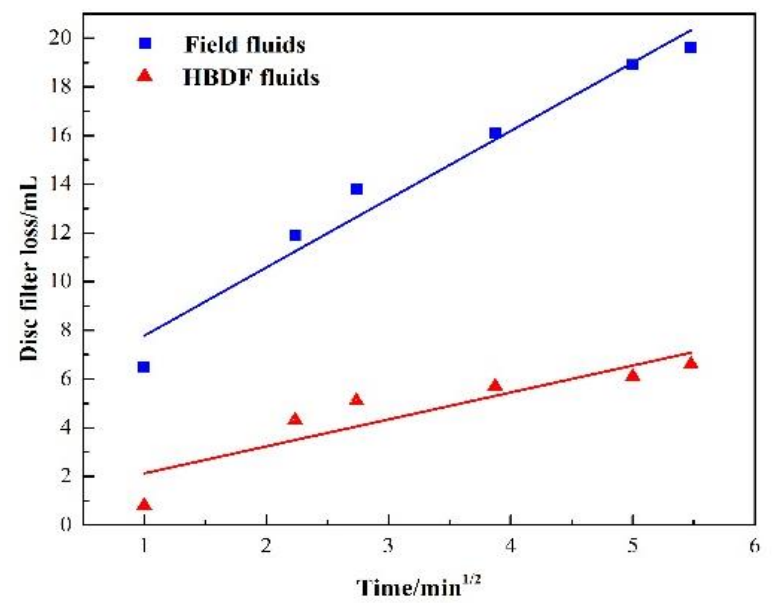

(b) Static infiltrate loss rate

Figure 1. Permeability plugging performance of the HBDF fluids

The Permeability Plugging Apparatus (PPA) and an ultralow permeability sand disc with a permeability of $400 \mathrm{mD}$ were used to evaluate the permeability plugging performance of the HBDF system, as shown in Figure 1(a), the PPA filtrate loss of the current field drilling fluid system is relatively high (39.2 $\mathrm{mL}$ ), while the PPA filtrate loss of the proposed HBDF system is significantly lower, which is only $13.2 \mathrm{~mL}$. According to Figure 1(b), the instantaneous infiltrate loss of the current field drilling fluid system is $5.0 \mathrm{~mL}$ and its static infiltrate loss rate is $2.8 \mathrm{~mL} / \mathrm{min}^{1 / 2}$, while for the proposed HBDF system, the instantaneous infiltrate loss is $1.0 \mathrm{~mL}$, and the static infiltrate loss rate is $1.1 \mathrm{~mL} / \mathrm{min}^{1 / 2}$, indicating that the system has good performance in terms of permeability plugging.

\subsection{Evaluation of lubrication performance}

With the help of the extreme pressure lubrification meter and the mud-cake adhesion coefficient tester, the extreme pressure lubrication coefficient and the mud-cake adhesion coefficient of the $\mathrm{HBDF}$ system after $150^{\circ} \mathrm{C} / 16 \mathrm{~h}$ hot rolling were measured, and the results show that, after adding the green lubricant HB-3, the extreme pressure lubrication coefficient (0.087) and the mud-cake adhesion coefficient (0.0204) of the HBDF system are relatively low, which can meet the requirements of directional and horizontal well sections for friction reduction; at the same time, it has also avoided problems such as the environmental protection and the cost issues of on-site oil mixing.

\subsection{Evaluation of environmental protection performance}

Table 6. Environmental protection performance of HBDF fluids

\begin{tabular}{ccc}
\hline NO. & Items & Results/(mg/L) \\
\hline 1 & $\mathrm{Hg}$ & $2.51 \times 10^{-3}$ \\
2 & $\mathrm{Cr}$ & 0.238 \\
3 & $\mathrm{Cr}^{6+}$ & 0.057 \\
4 & $\mathrm{Ni}$ & $<0.05$ \\
5 & $\mathrm{Cu}$ & 0.084 \\
6 & $\mathrm{Ge}$ & $<0.05$ \\
7 & $\mathrm{Zn}$ & 1.46 \\
8 & $\mathrm{As}$ & 0.075 \\
9 & $\mathrm{EC} 50$ & $>10^{5}$ \\
\hline 10 & $\mathrm{pH}$ & 9 \\
\hline 11 & BOD $_{5} / \mathrm{COD}_{\mathrm{Cr}}$ & $16.2 \%$ \\
\hline
\end{tabular}

Table 6 shows the evaluation results of the environmental protection performance of the proposed system. The color of the HBDF system is light gray, the biological toxicity $\mathrm{EC}_{50}$ value is greater than $10^{5} \mathrm{mg} / \mathrm{L}$, the biodegradability $\mathrm{BOD}_{5} / \mathrm{COD}_{\mathrm{Cr}}$ value is $16.2 \%$, the system is non-toxic and easily biodegradable; and the content of heavy metal elements and volatile phenols can meet the national second-level sewage discharge standards. 


\section{FIELD APPLICATION TEST}

At present, the proposed HBDF system has been applied in more than 10 wells in the Q15, Z23, Y229 and other zones of the SL oilfield, and achieved good on-site application results, which has provided a good technical support for the research on green drilling fluids for the green development of oil and gas fields. At Well Q15-X, the Dongying Formation in the upper part produces a lot of mud, and the Shahejie Formation in the lower part collapses easily, therefore, enhancing the hydration inhibition and plugging properties of the drilling fluid system is the key measure to restraining the hydration and mud production of Dongying Formation and preventing the collapse of the Shahejie Formation.

The field test results show that the proposed HBDF system has stable rheological and infiltrate loss performance, good anti-pollution ability, easy maintenance, good hydration inhibition and plugging and anti-collapse performance, and good lubrication performance. The borehole expansion rate of the test well section is only $1.53 \%$, and the one-time success rate of electrical logging and casing running is $100 \%$. In addition, after the drilling is completed, the biological toxicity test result of the drilling fluids is $\mathrm{EC}_{50}$ value $>10^{5} \mathrm{mg} / \mathrm{L}$, indicating that the system has good environmental protection performance.

\section{CONCLUSIONS}

(1) Based on non-toxic and easily degradable natural polymers, this study developed a series of new-type supporting treatment agents for green water-based drilling fluids, and proposed a new green water-based drilling fluid system (HBDF). The system has a biological toxicity $\mathrm{EC}_{50}$ value less than $10^{5} \mathrm{mg} / \mathrm{L}$ and a biodegradability $\mathrm{BOD}_{5} / \mathrm{COD}_{\mathrm{Cr}}$ value more than $15 \%$, which can meet the non-toxic and easily biodegradable environmental protection requirements.

(2) The proposed HBDF system has good rheological and infiltrate loss performance, shale hydration inhibition performance, and anti-pollution performance; its heat resistance reaches $150^{\circ} \mathrm{C}, \mathrm{FL}_{\mathrm{API}}$ is $4.2 \mathrm{~mL}, \mathrm{FL}_{\mathrm{HTHP}}$ is $12 \mathrm{~mL}$, biological toxicity $\mathrm{EC}_{50}$ value $>10^{5} \mathrm{mg} / \mathrm{L}$, biodegradability $\mathrm{BOD}_{5} / \mathrm{COD}_{\mathrm{Cr}}$ value is $16.2 \%$, and it also has good environmental protection performance.

(3) Field test results indicate that the proposed system has stable rheological and infiltrate loss performance, good antipollution ability, easy maintenance, good hydration inhibition and plugging and anti-collapse performance, the biological toxicity of the system after drilling can meet environmental protection requirements, therefore, the system is of high promotion and application value.

\section{REFERENCES}

[1] Han, L.J., Li, G.R. (2019). Progress, development trends, and outlook for drilling environmental protection technologies in the Shengli Oilfield. Petroleum Drilling Techniques, 47(3): 89-94. https://doi.org/10.11911/syztjs.2019057

[2] Liu, J.Y. (2018). New research progress on high performance environmental friendly water-based drilling fluid technology. Advances in Fine Petrochemicals, 19(6): 33-38. https://doi.org/10.3969/j.issn.10098348.2018.06.009

[3] Wu, C.Y., Liang, G.C., Feng, B.H., Yang, Z.G. (2005). Present state of offshore drilling fluid and its development direction. Fault-Block Oil and Gas Field, 12(3): 69-71. https://doi.org/10.3969/j.issn.10058907.2005.03.024

[4] Tehrani, A., Young, S., Gerrard, D., Fernandez, J. (2009). Environmentally friendly water based fluid for HT/HP drilling. SPE International Symposium on Oilfield Chemistry, the Woodlands. Society of Petroleum Engineers. https://doi.org/10.2118/121783-MS

[5] Hu, J.J., Sun, Q., Xia, X.C., Wei, Z.L., Ji, T., Xiang, T. (2014). Development and application of environmentfriendly drilling fluid GREEN-DRILL. Petroleum Drilling Techniques, 42(2): 75-79.

[6] Liu, J.Y., Li, G.R., Xia, Y. (2020). Technical progress on environmental-friendly, high-performance water-based drilling fluids. Environmental and Earth Sciences Research Journal, 7(3): 121-126. https://doi.org/10.18280/eesrj.070305

[7] Zhang, Y.Q., Hu, J.D., Xu, P.C., Zheng, X., Cao, J., Wang, Y.Q. (2019). Development and application of the environmentally friendly HL-FFQH water base drilling fluid. Drilling Fluid \& Completion Fluid, 36(4): 437-441. https://doi.org/10.3969/j.issn.1001-5620.2019.04.007

[8] Zheng, L.H., Zhou, J.H., Wan, Y.S., Lin, Q. (2007). The Modified Natural-macromolecule drilling fluids. Natural Gas Industry, 27(8): 75-78. https://doi.org/10.3321/j.issn:1000-0976.2007.08.023

[9] Liu, J.Y., Guo, B.Y., Wang, Y., Chai, J.P., Chen, E.D. (2020). Study and application of environmentally friendly water base drilling fluid in Shengli Oilfield. Drilling Fluid \& Completion Fluid, 37(1): 64-70. https://doi.org/10.3969/j.issn.1001-5620.2020.01.010

[10] Wu, X.L., Yan, L.L., Wang, L.H., Wang, F.Y. (2018) Progress in the study of environmentally friendly drilling fluid filtration reducer. Drilling Fluid \& Completion Fluid, 35(3): 8-16. https://doi.org/10.3969/j.issn.10015620.2018.03.002

[11] Chen, S.Q., Qiu, Z.S., Zhong, H.Y., Zhang, Q., Yan, F., Liu, S.J. (2019). Preparation and performance evaluation of a drilling fluid microsphere starch filter loss reducer. Drilling Fluid \& Completion Fluid, 36(4): 414-419. https://doi.org/10.3969/j.issn.1001-5620.2019.04.003

[12] Liu, J., Guo, B., Li, G., Wang, B., Chai, J. (2019). Synthesis and performance of environmental friendly starch based filtrate reducers for water based drilling fluids. Fresenius Environmental Bulletin, 28(7): 56185623.

[13] Qiu, Z., Wang, W., Dong, B., Wang, H., Bao, D. (2015). Study and application of micro-nano plugging technology. Drilling Fluid \& Completion Fluid, 32(2): 610 . https://doi.org/10.10.3696/j.issn.10015620.2015.02.002

[14] Liu, J.Y., Guo, B.Y. (2019). Study on water-based drilling fluid for strengthening wellbore of horizontal shale gas wells. Journal of Xi'an Shiyou University (Natural Science), 34(2): $\quad 86-92, \quad 98$. https://doi.org/10.3969/j.issn.1673-064X.2019.02.013 